\title{
Sterol Biosynthesis from Acetate and the Fate of Dietary Cholesterol and Desmosterol in Crabs
}

\author{
Shin-ichi Teshima, Akio Kanazawa, and Haruhito OKamoto*
}

(Received May 24, 1976)

\begin{abstract}
This paper deals with the sterol-synthesizing ability and the fate of dietary sterols, cholesterol and desmosterol, in the crabs, Sesarma dehaani and Helice tridens. Injected acetate-1-14 $\mathrm{C}$ was not incorporated into either squalene or sterols in the above crabs. This suggested that the sterol-synthesizing ability from acetate is absent or weak in the crabs, $S$. dehaani and $H$. tridens. The apparent percentage absorptions of dietary cholesterol and desmosterol from the digestive tracts were 91.9 and 90.9 , respectively. The ingested cholesterol and desmosterol were metabolized to steryl esters and polar compounds but only slightly to water-soluble sterols. Also, it was shown that the crab, S. dehaani, is capable of converting desmosterol to cholesterol.
\end{abstract}

Recent investigations have demonstrated the unique aspects of sterol metabolism in marine crustaceans ${ }^{1)}$ : that is, crustaceans are lacking in sterol-synthesizing ability ${ }^{2-10}$, and require cholesterol and other sterols as essential substances for their normal growth ${ }^{11,12)}$. However, the sterol metabolism in crustaceans, especially in terrestrial and brackish species, is not clarified so fully. Hence, the authors have intended to obtain further information about the sterol metabolism in crustaceans. This paper deals with the biosynthesis of sterols and the intestinal absorption and metabolic fate of dietary sterols in the crabs, Sesarma dehaani and Helice tridens.

\section{Materials and Methods}

Crabs Generally, $S$. dehaani burrows in the marsh and meadow near seashore, and $H$. tridens dwells in the marsh of estuary and seashore ${ }^{13}$. In this study, the crabs were collected at Ibusuki, Kagoshima, Japan, during March and transported to this laboratory. They were maintained on a short-necked clam, Tapes philippinarum, in a wooden box until use.

Chromatography Gas-liquid chromatography (GLC) was conducted with a Shimadzu GC-4BPF using the columns of $1.5 \% \mathrm{OV}-17(3.0 \mathrm{~m}$ long $\times 4 \mathrm{~mm}$ i.d., column temperature $\left.233^{\circ} \mathrm{C}\right)$ and $3.0 \%$ OV-17 $\left(3.0 \mathrm{~m}\right.$ long $\times 6 \mathrm{~mm}$ i.d., column temperature $\left.265^{\circ} \mathrm{C}\right) .{ }^{14,15)}$ In thin-layer chromatography (TLC), two types of adsorbent were used; Kieselgel G with benzene-ethyl acetate $(4: 1)$ or cyclohexane-ether $(7: 3)$ and a mixture of Kieselgel Gsilver nitrate (4:1) $\left(\mathrm{AgNO}_{3}-\mathrm{TLC}\right)$ with hexane-benzene (5:3). Florisil column chromato-

* Laboratory of Fisheries Chemistry, Faculty of Fisheries, Kagoshima University, Kagoshima, Japan. (手島新一一金沢昭夫・岡本春人：鹿览島大学水産学部) 
graphy was carried out by using deactivated Florisil (60-100 mesh, Nakarai Chemical Co.) with $6 \%$ of distilled water. The column of Florisil $(20 \mathrm{~g}, 54 \mathrm{~cm}$ long $\times 10 \mathrm{~mm}$ i.d.) was eluted with $50 \mathrm{~m} l$ of $5 \%$ ether, $80 \mathrm{ml}$ each of $15 \%$ ether, $25 \%$ ether, and $50 \%$ ether in hexane, $80 \mathrm{ml}$ of ether, $100 \mathrm{ml}$ each of $2 \%$ methanol, $5 \%$ methanol, $10 \%$ methanol, $20 \%$ methanol, and $30 \%$ methanol in ether; fraction $(10 \mathrm{~m} l)$ was collected and monitored by TLC on Kieselgel $G$ with benzene-ethyl acetate (4:1). Column chromatography on a mixture of silicic acid-silver nitrate (5:1) $\left(\mathrm{AgNO}_{3}\right.$-column) was performed as reported previously ${ }^{16)}$. The column packed with a silver nitrate-impregnated silicic acid $(10 \mathrm{~g}$, $13.5 \mathrm{~cm}$ long $\times 1.0 \mathrm{~cm}$ i.d.) was eluted with $50 \mathrm{ml}$ each of $0 \%, 10 \%$, and $15 \%$ benzene in hexane, and then $45 \mathrm{ml}$ each of $20 \%, 23 \%, 26 \%, 29 \%, 32 \%, 38 \%, 41 \%, 44 \%, 47 \%, 50 \%$, $53 \%$ and $56 \%$ benzene in hexane; fraction $(15 \mathrm{ml})$ was collected and monitored by GLC on $1.5 \%$ oV -17 .

Radiochemicals and radioactive measurement Acetate- $1-{ }^{14} \mathrm{C}(45-60 \mathrm{mCi} / \mathrm{mM})$, cholesterol-4- ${ }^{14} \mathrm{C}(50-60 \mathrm{mCi} / \mathrm{mm})$, and desmosterol- $26{ }^{-14} \mathrm{C}(40-60 \mathrm{mCi} / \mathrm{mm})$ were purchased from a Radiochemical Centre, Amersham, England. The purity of radioactive sterols was checked by TLC. Radioactivity of sample was measured with a Beckman liquid scintillation counter, model LS-230, using the toluene solution of 2,5-diphenyloxazole (PPO) $(0.6 \%)$ as a scintillator.

Injection of acetate-1- ${ }^{14} \mathrm{C}$ The crabs, $S$. dehaani and $H$. tridens, about $15 \mathrm{~g}$ in average body weight, were injected with $25 \mu \mathrm{Ci}$ and $75 \mu \mathrm{Ci}$ of acetate- $1{ }^{14} \mathrm{C}$, respectively, and then maintained on a short-necked clam for 10 days. From the whole body of crabs injected with acetate- $1-{ }^{14} \mathrm{C}$, lipids, unsaponifiable matters, and crude $3 \beta$-sterols were isolated by the same method as described previously ${ }^{9}$. The radioactivity of these lipid fractions was measured by means of the liquid scintillation counter and radioautography.

Dietary supplement of radioactive sterols For the purpose of investigating the fate of dietary sterols, the specimens of $S$. dehaani were divided into two groups, and they were fed on the synthetic diets ${ }^{17,18)}$ containing $0.5 \%$ level of cholesterol together with either $5 \mu \mathrm{Ci}$ of cholesterol-4-14 $\mathrm{C}$ or $1 \mu \mathrm{Ci}$ of desmosterol-26- ${ }^{14} \mathrm{C}$. The methods for preparation of synthetic diets were essentially similar to those in the previous paper ${ }^{18)}$. The amount of intaked sterols was estimated by the measurement of radioactivity (dpm) in the excreta and remains of diets 24 hours after the supplement of diets, and then the crabs were reared on the synthetic diet containing $0.5 \%$ level of non-radioactive cholesterol for successive 6 days.

Fractionation of the metabolites from radioactive sterols Seven days after the feeding of radioactive sterols, the whole body of crabs were subjected to analysis for the investigation of metabolites. The crabs were homogenized with chloroform-methanol-water (2:2:1) by the method of BLIGH and DYER ${ }^{19)}$ and separated into the chloroform layer (Fraction A), aqueous layer, and residue. The residue after extraction with organic 
solvents was refluxed 3 times with distilled water for 1 hour, and the resultant extract was added to the aqueous layer. The combined aqueous extracts were treated with chloroform-methanol-water $(2: 2: 1) 4$ times to remove small amounts of organic solventextractable lipids. From the aqueous extract so obtained (water-soluble steroid fraction), steroids were released as follows; the treatment with methanolic hydrochloric acid and alkaline pyrogallol by the methods of $\mathrm{PRYCE}^{20)}$ afforded Fraction $\mathrm{B}$ and Fraction $\mathrm{C}$, respectively.

Fraction A was further separated into the steryl esters, free sterols, and 'polar compounds' by column chromatography on Florisil. In this chromatography, steryl esters and free sterols were eluted with $5 \%$ ether and $25 \%$ ether in hexane, respectively. The materials eluted with the solvents more polar than $50 \%$ ether in hexane were combined as polar compounds.

In order to investigate the transformation of sterol molecules, the sterols from the steryl ester and free sterol fractions were acetylated with dry pyridine-acetic anhydride (1:1), and then the radioactive steryl acetates were subjected to $\mathrm{AgNO}_{3}-\mathrm{TLC}, \mathrm{AgNO}_{3}$ column chromatography, and preparative GLC on $3.0 \% \mathrm{OV}-17$ followed by radioactive determination of the trapped samples.

\section{Results and Discussion}

Sterol biosynthesis Table 1 indicates the incorporation of acetate- $1{ }^{14} \mathrm{C}$ into the lipid fractions of crabs, $S$. dehaani and $H$. tridens 10 days after the injection of acetate $-1{ }^{14} \mathrm{C}$. In both crabs, a relatively high radioactivity was recovered in the lipid and unsaponifiable matter fractions, but the crude $3 \beta$-sterols were labelled to a extremely low degree. The successive crystallizations of crude $3 \beta$-sterols from methanol resulted in the complete loss

Table 1. Radioactivity of lipid fractions isolated from the crabs, $S$. dehaani and $H$. tridens, 10 days after injection of acetate- $1{ }^{14} \mathrm{C}$.

\begin{tabular}{|c|c|c|c|c|c|c|}
\hline \multirow{2}{*}{ Lipid fraction } & \multicolumn{3}{|c|}{ S. dehaani } & \multicolumn{3}{|c|}{ H. tridens } \\
\hline & $\begin{array}{l}\text { Weight } \\
\text { (g) }\end{array}$ & $\begin{array}{l}\text { Radioactivity } \\
\text { (dpm) }\end{array}$ & $\begin{array}{c}\text { Specific } \\
\text { activity } \\
(\mathrm{dpm} / \mathrm{mg}) \\
\end{array}$ & $\begin{array}{c}\text { Weight } \\
(\mathrm{g}) \\
\end{array}$ & $\begin{array}{l}\text { Radioactivity } \\
\text { (dpm) }\end{array}$ & $\begin{array}{c}\text { Specific } \\
\text { activity } \\
\text { (dpm/mg) }\end{array}$ \\
\hline Fresh weight ${ }^{* 1}$ & 87.0 & - & - & 73.0 & - & - \\
\hline Dosage of acetate-1 $-^{14} \mathrm{C}$ & - & $5.50 \times 10^{7}$ & - & - & $16.5 \times 10^{7}$ & - \\
\hline Total lipids & 1.09 & 535,000 & 429 & 1.35 & 560,000 & 416 \\
\hline$(\% \text { Incorporation })^{* 2}$ & - & $(0.97)$ & - & - & $(0.34)$ & - \\
\hline Unsaponifiable matters & 0.136 & 48,100 & 354 & 0.137 & 46,700 & 341 \\
\hline Crude $3 \beta$-sterols & 0.072 & 5,850 & 81.7 & 0.070 & 3,170 & 45.2 \\
\hline $\begin{array}{l}\text { 38-Sterols after } 1 \text { st } \\
\text { recrystallization }\end{array}$ & - & - & 3.5 & - & - & 0.7 \\
\hline $\begin{array}{l}3 \beta-\text { Sterols after } 2 \text { nd } \\
\text { recrystallization }\end{array}$ & - & 一 & 0 & 一 & - & 0 \\
\hline
\end{tabular}

*1 Five animals of crabs were injected with acetate-1 ${ }^{14} \mathrm{C}(61 \mathrm{mCl} / \mathrm{mm})$.

*2 Percentage incorporation of administrated radioactivity into lipids. 
of radioactivity. An aliquot of unsaponifiable matter was subjected to TLC on Kieselgel $G$ with benzene-ethyl acetate $(4: 1)$ and then autoradiographed by exposing the plate for 4 weeks. The autoradiogram so obtained gave no radioactive spot corresponding to squalene, lanosterol (dimethylsterol), and cholesterol (desmethylsterol). These data suggested that the sterol-synthesizing ability from acetate was absent in the crabs, $S$. dehaani and $\boldsymbol{H}$. tridens, or extremely weak. Also, the failure of detection of radioactive squalene and dimethylsterols assumed that the sterol biosynthesis in these crabs may be blocked at steps before the cyclization of fanesylpyrophosphate to squalene. The absence of sterol biosynthesis in crustaceans has been also demonstrated in some species; a crayfish, Astacus astacus ${ }^{2-4,7)}$, lobster, Homarus gammarus $^{3,5)}$, crab, Cancer pagurus ${ }^{6}$, blue crab, Callinectes sapidus $^{8)}$, prawn, P. japonicus ${ }^{9)}$, spiny lobster, Panulirus japonica ${ }^{9}$, crab, Portunus trituberculatus ${ }^{91}$, and Artemia salina ${ }^{10)}$.

Table 2. The composition of sterols isolated from the crabs, $S$. dehaani and $H$. tridens.

\begin{tabular}{lcc}
\multicolumn{1}{c}{ Sterol } & \multicolumn{2}{c}{$\%$ Composition } \\
\cline { 2 - 3 } & S. dehaani & H. tridens \\
Cholesterol & 80.9 & 91.7 \\
24-Methylcholesta-5,22-dienol & trace & trace \\
24-Methylcholesterol & 4.3 & 4.6 \\
24-Ethylcholesta-5,22-dienol & 4.9 & 0.5 \\
24-Ethylcholesterol & 5.6 & 2.2 \\
Fucosterol & 4.3 & 0.9 \\
\hline
\end{tabular}

Table 2 shows the constituent sterols of crude sterol fractions from the crabs, $S$. dehaani and $H$. tridens. The two species of crabs contained cholesterol as exclusively major components and other minor sterols such as 24-methylcholesta-5,22-dienol, 24methylcholesterol, 24-ethylcholesta-5,22-dienol, 24-ethylcholesterol, and fucosterol. The percentage composition of sterols in the above two crustaceans examined was essentially similar to those of other crustaceans ${ }^{1,21-23)}$.

Absorption and retention of dietary sterols The apparent percentage absorption of cholesterol and desmosterol from the digestive tracts in the crab, S. dehaani, was estimated by using tracer techniques. As shown in Table 3, the percentage absorptions of cholesterol-

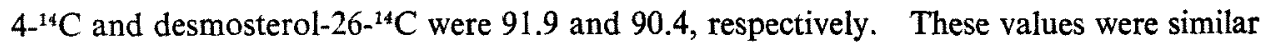
to that of cholesterol in the prawn, $P$. japonicus ${ }^{24)}$, which was determined by an indirect method using chromium oxide as indicators. In vertebrates, bile acids besides phospholipids are generally known to be necessary for the effective absorption of cholesterol from the intestine. In the case of the crustaceans, however, it has been reported that the gastric juices of crab, C. pagurus, contained no bile acids ${ }^{25)}$ but other types of emulsifier, fatty acylsarcosyltaurine ${ }^{26)}$. Therefore, it seems to be of interest to clarify the mechansim 
Table 3. Apparent percentage absorption of dietary cholesterol-4- ${ }^{14} \mathrm{C}$ and desmosterol$26{ }^{14} \mathrm{C}$ in the crab, $S$. dehaani.

\begin{tabular}{ccl}
\hline \multicolumn{2}{c}{ Radioactivity $\left(\mathrm{dpm} \times 10^{3}\right)$} & \\
\hline Dietary sterol & \multicolumn{1}{c}{ Remarks } \\
\hline 16,600 & 1,950 & Sterol supplied \\
3,350 & 187 & Sterol in the remains of diet \\
1,070 & 169 & Sterol in the excreta \\
13,250 & 1,763 & Sterol intaked \\
12,180 & 1,594 & Sterol retained in the body after 24 hours \\
91.5 & 90.4 & Apparent \% absorption of sterol \\
\hline
\end{tabular}

* The crabs were fed on radioactive sterols, and then the apparent \% absorption was determined after 24 hours.

for intestinal absorption of sterols in crustaceans in the viewpoint of comparative biochemistry.

Fate of ingested cholesterol and desmosterol Seven days after the feeding of cholesterol-4- ${ }^{14} \mathrm{C}$ and desmosterol-26. ${ }^{14} \mathrm{C}$, the radioactive compounds were extracted from the whole body of crab, $S$. dehaani, and separated into the several fractions. As shown in Table $4,61.1 \%$ and $73.6 \%$ of the ingested radioactivity were recovered in the crabs fed on cholesterol-4- ${ }^{-14} \mathrm{C}$ and desmosterol- $26-{ }^{14} \mathrm{C}$, respectively. This result suggested that the turnover of both sterols proceeds more slowly than in vertebrates possessing the sterolsynthesizing ability from lower units. The chloroform-methanol extract (Fraction A) gave a high radioactivity but the water soluble-steroid fraction (Fractions $\mathrm{B}$ and $\mathrm{C}$ ) showed no significant radioactivity in both crabs fed on radioactive cholesterol and desmosterol. The Florisil column chromatography of Fraction A demonstrated that the large

Table 4. Fate of radioactive sterols in the crab, S. dehaani, 7 days after the feeding of cholesterol $-4{ }^{14} \mathrm{C}$ and desmosterol-26- ${ }^{14} \mathrm{C}$.

\begin{tabular}{ccc}
\hline & Radioactivity (dpm) recovered \\
& Fraction & Dietary sterol \\
& Cholesterol-4 ${ }^{14} \mathrm{C}$ & Desmosterol-26- ${ }^{14} \mathrm{C}$ \\
\cline { 2 - 3 } & & \\
Organic solvent-soluble steroids & $7,467,000$ & $1,170,000$ \\
Fraction A & 855,000 & 131,000 \\
Steryl esters & $6,180,000$ & 917,000 \\
Free sterols & 387,000 & 122,000 \\
Polar compounds & & 1,130 \\
Water-soluble steroids & 1,560 & 95 \\
Fraction B & 50 & $(73.6)$ \\
Fraction C & $(61.1)$ & \\
Retention of absorbed sterol & &
\end{tabular}

Fraction A, chloroform-methanol extract; Fraction B, steroids obtained after treatment with methanolic hydrochloric acid; Fraction $\mathrm{C}$, steroids obtained after treatment with alkaline pyrogallol. 
portion of radioactive compounds was present as free sterols. However, a significant radioactivity was also associated with steryl ester and polar compounds. An aliquot of Fraction A was subjected to TLC on Kieselgel $G$ with cyclohexane-ethyl acetate $(7: 3)$ and autoradiographed. The autoradiogram so obtained showed the presence of radioactive steryl esters ( $\operatorname{Rf} 0.51$ ), free sterols ( $R f 0.33$ ), and polar compounds ( $\operatorname{Rf} 0.14$ and 0.01 ) in both samples from the crabs fed on cholesterol-4 $-{ }^{14} \mathrm{C}$ and desmosterol-26- $-{ }^{14} \mathrm{C}$. These results indicated that a part of ingested cholesterol and desmosterol was metabolized to some steryl esters and polar compounds in the crab, S. dehaani. In the prawn, $P$.japonicus, cholesterol was also found to be modified to cholesteryl ester and polar compounds ${ }^{27}$. Also, the spiny lobster, $P$. japonica, has been proved to be capable of converting cholesterol to steroid hormones ${ }^{28}$. In addition, SPAZIANI and KATER have demonstrated tentatively the bioconversion of cholesterol to ecdysones in the Y-organs of a crab, Hemigrapsus $n u d u s^{29}$. Considering these informations, it seems likely that cholesterol and desmosterol are probably used as precursors for steroid hormones and molting hormones in the crab, S. dehaani.

Transformation of sterol molecules In order to check the transformation of sterol molecules in the crabs, $\dot{S}$. dehaani, fed on cholesterol-4- ${ }^{-14} \mathrm{C}$ and desmosterol- $26-{ }^{14} \mathrm{C}$, the radioactive sterols from the esterified and free sterol fractions were acetylated and then analyzed by $\mathrm{AgNO}_{3}-\mathrm{TLC}, \mathrm{AgNO}_{3}$-column chromatography, and preparative GLC. Regarding both the esterified and free sterol fractions, the autoradiography after $\mathrm{AgNO}_{3}$ TLC showed that the ingested cholesterol-4- $\mathrm{C}^{24}$ remained almost unchanged in the body, but a small portion of it was converted to more polar sterol than 24-methylenecholesterol. On the other hand, desmosterol-26- ${ }^{14} \mathrm{C}$ was found to be converted to cholesterol and polar sterol in $\mathrm{AgNO}_{3}-\mathrm{TLC}$, and these metabolites were present in both the free and esterified forms. The further characterization of polar sterol from cholesterol-4- ${ }^{14} \mathrm{C}$ and desmosterol${ }^{26}{ }^{14} \mathrm{C}$ was not performed in the present study. To confirm the identity of cholesterol $-{ }^{14} \mathrm{C}$ as the metabolite of desmosterol-26- ${ }^{14} \mathrm{C}$, the radioactive sterols (as acetates) were further analyzed by $\mathrm{AgNO}_{3}$-column chromatography and preparative GLC on $3.0 \% \mathrm{OV}-17$. As shown in Figs. 1 and 2, the presence of radioactive cholesterol was ascertained. These results indicated that the crab, $S$. dehaani, is capable of converting desmosterol to cholesterol as well as the marine prawn, $P$. japonicus ${ }^{30)}$, and shrimp, Palaemon serratus ${ }^{31}$.

Literatures have shown that some crustaceans contained substancial amounts of desmosterol in their tissues ${ }^{23,32)}$, although the origin of it was obscure. The present study revealed that the formation of desmosterol from both acetate- $1-{ }^{14} \mathrm{C}$ and cholesterol- $4-{ }^{14} \mathrm{C}$ did not take place in the crab, S. dehaani. Since there is no evidence showing the de novo synthesis of desmosterol from lower units in crustaceans, as far as the authors know, it may be assumed that desmosterol occurring in crustacean tissues probably originates from dietary sources of $\mathrm{C}_{28^{-}}$and $\mathrm{C}_{29^{-}}$-sterols by means of dealkylation ${ }^{1)}$. 


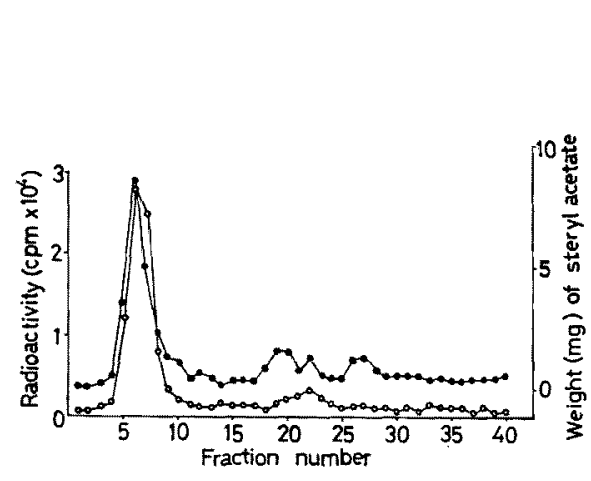

Fig. 1.

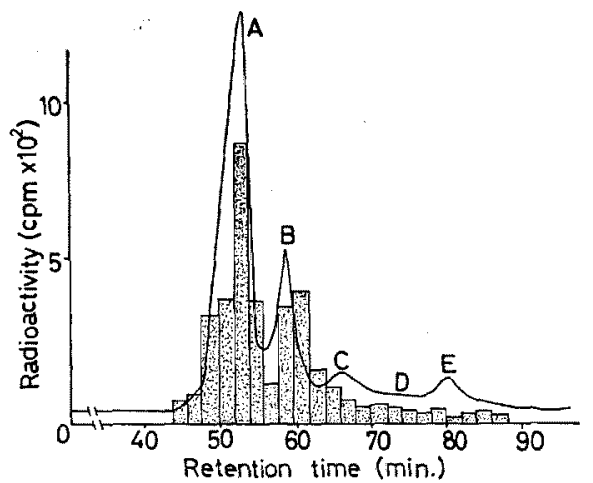

Fig. 2.

Fig. 1. Column chromatography of the radioactive sterols from free sterol fraction isolated from the crab, $S$. dehaani, fed on desmosterol- $26-{ }^{14} \mathrm{C}$.

The radioactive sterols (as acetates) were subjected to $\mathrm{AgNO}_{8}$-column chromatography, and then the radioactivity (cpm) of each fraction was determined with a liquid scintillation counter. The radioactive peak (fraction 4-9) corresponded to cholesteryl acetate. $\mathrm{O}-\mathrm{O}$, radioactivity; $-\mathrm{C}$, weight of steryl acetate.

Fig. 2. Preparative GLC on $3.0 \%$ OV -17 of the radioactive sterols from free sterol fraction isolated from the crab, $S$. dehaani, fed on desmosterol-26-14 $\mathrm{C}$.

The radioactive sterols (as acetates) were subjected to preparative GLC on $3.0 \%$ $\mathrm{OV}-17$, and the effluents were trapped in a collector at interval of 2 minutes. The radioactivity of trapped samples were measured with a liquid scintillation counter. A-E, the trace of mass in GLC; blotted bars, radioactivity. Peaks A, B, C, D, and E corresponded to cholesteryl acetate, desmosteryl acetate, 24-methylcholesteryl acetate, 24-ethylcholesta-5, 22-dienyl acetate, and 24-ethylcholesteryl acetate, respectively.

\section{References}

1) S. Teshtma: Mem. Fac. Fish., Kagoshima Univ., 21, 69-147 (1972).

2) D. I. ZANDEE: Nature, 195, 814-815 (1962).

3) D. I. ZANDEE: ibid., 202, 1335-1336 (1964).

4) D. I. ZANDEE: Archs. Int. Physiol. Biochim., 74, 435-441 (1966).

5) D. I. ZANDEE: Comp. Biochem. Physiol., 20, 811-822 (1967).

6) A. VAN DEN OORD: ibid., 13, 461-463 (1964).

7) L. Gosselin: Archs. Int. Physiol. Biochim., 73, 543-544 (1965).

8) J. O. WhITney: Marine Biol., 3, 134-135 (1969).

9) S. Teshima and A. Kanazawa: Comp. Biochem. Physiol., 38B, 597-602 (1971).

10) S. Teshima and A. Kanazawa: This Bull., 37, 720-723 (1971).

11) A. Kanazawa, N. Tanaka, S. Teshma, and K. Kashiwada: ibid., 37, 211-215 (1971).

12) J. D. Castell, E. G. Mason, and J. F. CoveY: J. Fish. Res. Bd. Can., 32, 1431-1435 (1975).

13) H. SAKaI: In "New Illustrated Encyclopedia of the Fauna of Japan" (ed. by K. OKADA, S. UchuDA, and R. UcHIDA), Hokuryu-Kan, Tokyo, 1965, pp. 718-720.

14) S. Teshima, A. Kanazawa, and T. Ando: Mem. Fac. Fish., Kagoshima Univ., 20, 131-139 (1971).

15) S. Teshima and A. Kanazawa: Comp. Biochem. Physiol., 52B, 437-441 (1975).

16) S. Teshima, A. Kanazawa, and T. Ando: Mem. Fac. Fish., Kagoshima Univ., 22, 7-13 (1973).

17) K. KashiwadA and A. KanAZAWA: YOSHOKU, 7, 44-48 (1970).

18) A. Kanazawa, M. Shimaya, M. Kawasaki, and K. Kashiwada: This Bull., 36, 949-954 (1970).

19) E. G. Bligh and W. J. Dyer: Can. J. Biochem. Physiol., 37, 911-917 (1959).

20) R. J. PRYCE: Phytochem., 10, 1303-1307 (1971). 
21) D. R. IdLeR and P. WiSEMAN: Int. J. Biochem., 2, 91-98 (1971).

22) S. Yasuda: Comp. Biochem. Physiol., 44B, 41-46 (1973).

23) S. Teshima and A. Kanazawa: This Bull., 37, 63-67 (1971).

24) S. Teshima, A. Kanazawa, and H. OKamoto: ibid., 40, 1015-1019 (1974).

25) H. J. VonK: Archs. Int. Physiol. Biochim., 70, 67-85 (1962).

26) A. VAN den Oord, H. Danielsson, and R. PyHage: Nature, 203, 301-302 (1964).

27) J. B. Guary and A. Kanazawa: Comp. Biochem. Physiol, 46A, 5-10 (1973).

28) A. Kanazawa and S. Teshima: This Bull., 37, 891-903 (1971).

29) E. SpazIANi and S. B. Kater: Gen. Comp. Endocrinol., 20, 534-549 (1973).

30) S. Teshima and A. Kanazawa: Mem. Fac. Fish., Kagoshima Univ., 22, 15-19 (1973).

31) S. Teshima, H. J. Ceccaldi, J. Patrois, and A. Kanazawa: Comp. Biochem. Physiol, 50B, 485-489 (1975).

32) D. R. Ioler and P. Wiseman: Comp. Biochem. Physiol., 26, 1113-1117 (1968). 